\title{
The Effects of Using Paper and Electronic Monolingual English Learners' Dictionaries while Reading on Students In-depth Vocabulary knowledge
}

\begin{abstract}
:
Learning new words is a primary concern for most learners. Accordingly, many EFL students make use of English-English dictionaries, paper and electronic to develop their vocabulary. The purpose of this quasiexperimental study is to examine the effects of using dictionaries on students' in-depth vocabulary knowledge. The results showed that students' in-depth vocabulary knowledge improved when they used their dictionaries, in particular electronic ones. Thus, using dictionaries as a learning tool deserves more attention in the context of EFL vocabulary learning and teaching.
\end{abstract}

Key Words: Vocabulary Knowledge, Dictionary, Electronic Dictionary.

\author{
BENZITOUNI Amina Ouafa \\ Faculty of Letters and Languages \\ Department of Foreign Languages \\ University of Mentouri \\ Constantine
}

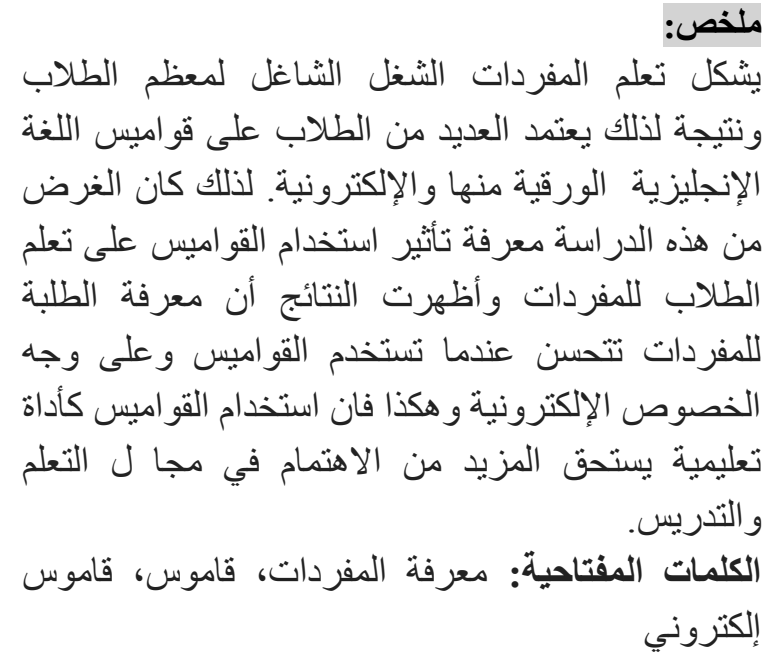

\section{Introduction :}

Reading is considered an important means by which students learn new words. However, developing vocabulary knowledge through reading is not an easy activity. Making erroneous inferences that lead to incorrect learning is among the major problems learners face when developing their vocabulary through reading. Moreover, if the meaning of new vocabulary items is grasped, still learners may not be able to pronounce, spell, or use those words. It is common for students to think that once they learn the meaning and spelling of a word, the job of learning that word is done. 
However, making a link between form and meaning is just the first step in vocabulary learning. In building vocabulary, we need to make sure that each word is learned and understood thoroughly.

EFL students should be given enough information on words to help them avoid mistakes in their use of the foreign language. This information is presented in most of learners' dictionaries that provide them with valuable data in every aspect of language. Many electronic dictionaries are also now available in a variety of formats as CD-ROM dictionaries and online dictionaries. They are all said to be innovative, user-friendly and providing information on current English.

Previous research on the effects of dictionary use on vocabulary knowledge has failed to produce a clear image that amply describes it. Until now, most studies have generally targeted paper dictionaries and look at the size of vocabulary ignoring the other aspects of word knowledge. That is why, this paper seeks to examine the effects of using monolingual English learners' dictionaries in electronic and paper form on students' in-depth word knowledge.

This paper addresses the following research questions:

$>$ What effects do dictionaries have on students' in-depth vocabulary knowledge?

$>$ Which type of dictionary, paper or electronic, leads to better in-depth vocabulary knowledge development?

\section{Vocabulary Knowledge}

The nature of vocabulary learning is complex and involves several components. Many people believe that knowing a word means knowing its meaning and form. However, a word is more than just familiarity with its meaning and form [1]. Nation [2] regards vocabulary knowledge as comprising a number of different sub-knowledge components. He generates a list that captures the key elements of word knowledge which are: the spoken form of the word, the written form of the word, the grammatical behavior of the word, the collocational behavior of the word, the frequency of the word, the stylistic register constraints of the word, the conceptual meaning of the word, and the associations the word has with other related words. How much students know about these aspects of word knowledge is referred to as in-depth vocabulary knowledge [3].

In-depth vocabulary knowledge lies in the semantic networks that relate words with the other types of information required to properly understand and use it [4]. Ordonez et al [5] point out that "although lexical knowledge is most commonly thought of and assessed as a number of words known, or breadth of vocabulary, it is now increasingly clear that richness of the representation of the words known is also a key dimension of variability." (p.719). 


\section{Dictionary Use and Vocabulary Learning}

Studies on the relationship between dictionary use and vocabulary learning are considered the most important areas of research on dictionary effectiveness. Diverse views are held on whether dictionaries must be used in EFL learning or not. Traditional methods of EFL teaching emphasized on learning grammar, translation, and reading literary works, rather than communicating with native speakers. The learner's native language was considered as a reference in EFL learning, and the use of bilingual dictionaries is unavoidable, and supported by teachers. Then, educationalists reacted against the grammar-translation method to the point of banning dictionary consultation in classrooms. They stressed learning how to communicate as a member of a specific socio-cultural community and emphasized on communicative competence which was liable to entail lexical knowledge, as well as syntactic, pragmatic, and cultural knowledge. The theory of communicative competence in the teaching of English as a foreign language led many teachers to use the target language in the classroom almost exclusively, to discourage dictionary use in classrooms, and to neglect teaching learners effective skills to use their dictionaries, preferring students to guess meanings from contexts [6].

Many scholars are in favor of implicit, naturalistic approaches to learn vocabulary. Honeyfield [7], for instance, advise EFL learners to use dictionaries scarcely, only as a last resort and consider learning vocabulary through consulting dictionaries a form of rote learning. Miller and Gildea [8] argue that dictionary consultation is a lengthy procedure. The learner has first to find the dictionary itself, then search for the intended word. Once the word is located, the right entry is found, and the various senses of the word are differentiated. The context of the original passage should be matched up with the contexts in the dictionary until the accurate decision is made. As a result, this long process can interrupt the continuity of the learner's thought and make $\mathrm{him} /$ her forget the context in which the unknown word occurred.

In addition, McCarthy and Dolezal [9] examined the effectiveness of The American Heritage Dictionary for advanced EFL students through a multiple choice vocabulary test. The students were divided into three groups: Participants in the first group were allowed to use the dictionary; students in the second group were given a short story to read (which included the tested vocabulary) and were not allowed to consult their dictionaries; participants in the third group had access to the dictionary and were given the story too. The groups scored 69\%, 68\%, and 79\%, respectively. So, McCarthy and Dolezal noted that dictionaries alone are unhelpful to learn vocabulary, and that the presence of contextual information is important.

Many other researches, however, have demonstrated that relying on implicit vocabulary learning exclusively is insufficient. Researchers found out 
that guessing did not work well in a number of contexts and that dictionary use was sometimes inevitable. The limitations of implicit learning triggered researchers' interest in explicit vocabulary learning methods, such as dictionary use [2]. In their article on native students' dictionary use, exactly on their definitions, of receptive vocabulary learning, Nist and Olejnik [10] ask the following question: "Where has the idea come from that looking words up in a dictionary is the worst way for students to learn vocabulary" (p. 172).

Many studies demonstrate that consulting a dictionary is not detrimental to foreign language learning and that dictionary use is one of the best ways to learn new words. Dictionary users, generally, learn more words than those who do not use a dictionary and approach the unknown words through other strategies. In addition, words consulted in the dictionary are revealed to be kept in mind better than words learnt incidentally.

Knight [11], for example, used on-screen dictionaries to test dictionaries' effectiveness on vocabulary learning and reading comprehension of intermediate university students of Spanish. The students were randomly divided into dictionary and no dictionary users groups and were administered unexpected immediate and delayed tests after reading an article. Students' performance demonstrated that dictionary users did better than non-dictionary users. It was also found that lower-proficiency students benefited more from dictionary use than high-proficiency learners. Additionally, Hulstijn et. al. [12] found that dictionary use can improve vocabulary learning and retention. Dictionary users in their study retained words more than learners without access to dictionaries

Dictionary use is also said to facilitate autonomous learning, and so lessens students' dependence on teachers and parents when learning. Users, by referring to the introductory pages of the book, will be able to search through their dictionaries and find what they need. At last, they will be so satisfied with the dictionary and will continue using it in their learning [13].

Sökmen [14], on the other hand, notes that: "The pendulum has swung from direct teaching of vocabulary (the grammar translation method) to incidental (the communicative approach) and now, laudably, back to the middle: implicit and explicit learning." (p. 239). He emphasizes that dictionary use together with contextual information use are more effective than each independently to learn vocabulary. The combination of guessing meaning from context and dictionary use results in deeper processing, longer retention and successful learning of words [14].

\section{What do Learners Really Search in their Dictionaries?}

Various studies on dictionary use pointed out that the problem is not the effectiveness of the dictionary but the way the learner uses it. Dictionaries are not used as wholly as they should be. A lot of learners are ignorant of the riches that their monolingual dictionaries include. The majority of learners 
perceives the dictionary as a storehouse of meanings merely; it is not more than a means to consult the meaning of unknown words [11]. Neubach and Cohen [15] revealed through a think-aloud study that EFL learners, even, read the first definition only when referring to monolingual dictionaries as they think all the rest are just examples.

Besides, pronunciation usually attracts little interest and is overlooked and ignored by learners. Learners seem to find the symbols complex and decoding them time consuming. So, they prefer to guess the pronunciation from the spelling [16]. Likewise, style labels that provide information about words special uses are generally ignored by learners and are seen to tax them needlessly with more work though lexicographers insist on informing users of words which carry negative implications as taboo and informal words [17]. Atkins and Varantola [18] noticed that collocations are among the least sought information categories as students are ignorant of the notion of collocation, and lack the skills to look it up. Only $10 \%$ of advanced users were aiming at locating collocational information.

\section{The Electronic Dictionary Age}

EFL teaching and learning vocabulary surely draw on the rich variety of the lexicographical works available in English. The field of English pedagogical lexicography has manifested a rapid technological advance and innovative developments that took into account users' needs and teachers' and lexicographers' suggestions [19]. Since the introduction of corpus-based lexicography, dictionary making has known deep changes and has become very competitive. Publishers shifted focus from the dictionaries to the users [20]. Users' reference skills and needs in using dictionaries have become badly taken into account and the new learners' dictionaries have included many innovations which are claimed to be user-oriented, such as defining vocabulary, and indicating word frequency. Then, the subsequent phase in dictionary development has been dominated by computers and electronic dictionaries which are now progressively substituting their paper counterparts [18].

Electronic dictionaries provide learners with useful lexical data including semantic and syntactic information, examples, synonyms, hyponyms...etc, in addition to exercises, pictures and games. They also permit poor spellers to type in a "sound alike" version the needed word and select from a range of near matches the dictionary suggests [21]. The innovations in electronic dictionaries attract students to use them frequently which will be helpful for learning [22]. Koga [23], for instance, found that learners with electronic dictionaries acquired more words as they looked up considerably more words than those with paper dictionaries. He also found that students read 
faster in the electronic dictionary condition than in the paper dictionary condition.

Many researchers, however, are still in doubt of electronic dictionaries as an aid in learning and claim that these apparent modernizations are just versions of lexicographically old traditional paper dictionaries. They think that the simplicity and consistency of use may result in superficial processing of the searched words and will therefore be harmful to retention [24]. Weschler and Pitts [25] describe this fact as "the absorbing sponge syndrome... that ...is rarely squeezed".

\section{The Study}

The present study focuses on the effects of using English monolingual learners dictionaries on students' in depth vocabulary knowledge. In particular, this experiment investigates the degree of which students gained knowledge of 08 target words from reading a text without dictionary access, with paper dictionary access and with electronic dictionary access.

\subsection{Participants and setting}

The experiment was conducted at the Department of Letters and English language, University of Constantine 1 (Algeria). The number of participants was 60 students. They were divided into three groups: No dictionary group, paper dictionary group, and electronic dictionary group.

\subsection{Procedure}

The participants were pretested by the administration of a receptive vocabulary checklist of 37 words (taken from the text to be used in the experiment) to each subject a week before the experiment. The pretest aimed to identify the words which no student had prior knowledge of and that would subsequently be used in the test. From the results of this test, a list of unknown words was created to be used in the experiment.

The day of the experiment, the participants were divided equally into three groups; no dictionary group (20 students), paper dictionary group (20 students), and electronic dictionary group (20 students). Then the groups were asked to read a text under the three conditions. After that, in order to examine whether there will be any differences between the groups in terms of in-depth vocabulary learning of the target vocabulary items, eight exercises were administered. The order of the exercises was based on the amount of information each exercise provided and was as follows: spelling, pronunciation, word class, frequency, collocations, register constraints, meaning, and word-associations. Participants were given one exercise at a time.

\subsection{Description of the test}

The test consisted of eight exercises. The first exercise involved the completion of partial spellings of the target words. The second exercise involved the underlining of the correct pronunciation from two pronunciation options (one was wrong) of the target words. The third exercise involved the 
determination of the target words' word class. In the fourth exercise, students were asked to choose the exact frequency value among three quite different frequencies one of which was the correct one. In the fifth exercise, students were provided with the list of the target words and were asked to match them with their collocations. In the sixth exercise, the participants were required to select an appropriate word from two choices, based on the context provided. The seventh exercise involved matching words with their corresponding meanings. The last exercise required students to put each word in the corresponding list of association responses.

In designing the tests, six dictionaries were consulted: Collins Cobuild Advanced Dictionary, Longman Pronunciation Dictionary, Oxford Collocations Dictionary, Oxford Learners' thesaurus, Oxford Fowlers' Modern English Usage, A Frequency Dictionary of Contemporary English in addition to the British National Corpus (BNC) and the database of word associations"wordassociation.org ".

\subsection{Main Results and Discussion}

The findings of our study revealed that dictionary use resulted in more vocabulary gains than reading the text without a dictionary. Developments in students' vocabulary knowledge in the no dictionary group were in most of the exercises lower than the paper and electronic dictionary groups which suggest that reading alone is not a sufficient source to widen students' in-depth vocabulary knowledge.

Moreover, the results of this study indicate that electronic dictionary users were able to achieve higher percentages of correct answers than students who used printed dictionaries in the test. The high advantages of the electronic dictionary are probably what makes it better, compared to the paper dictionary. As Sharpe [26] puts it, "the advantage of the electronic dictionary and the familiarity of today's young people with electronic devices will eventually relegate the printed notion of 'dictionary' to a secondary sense." (p. 49). The graph below summarises the results of the experiment in greater details. 


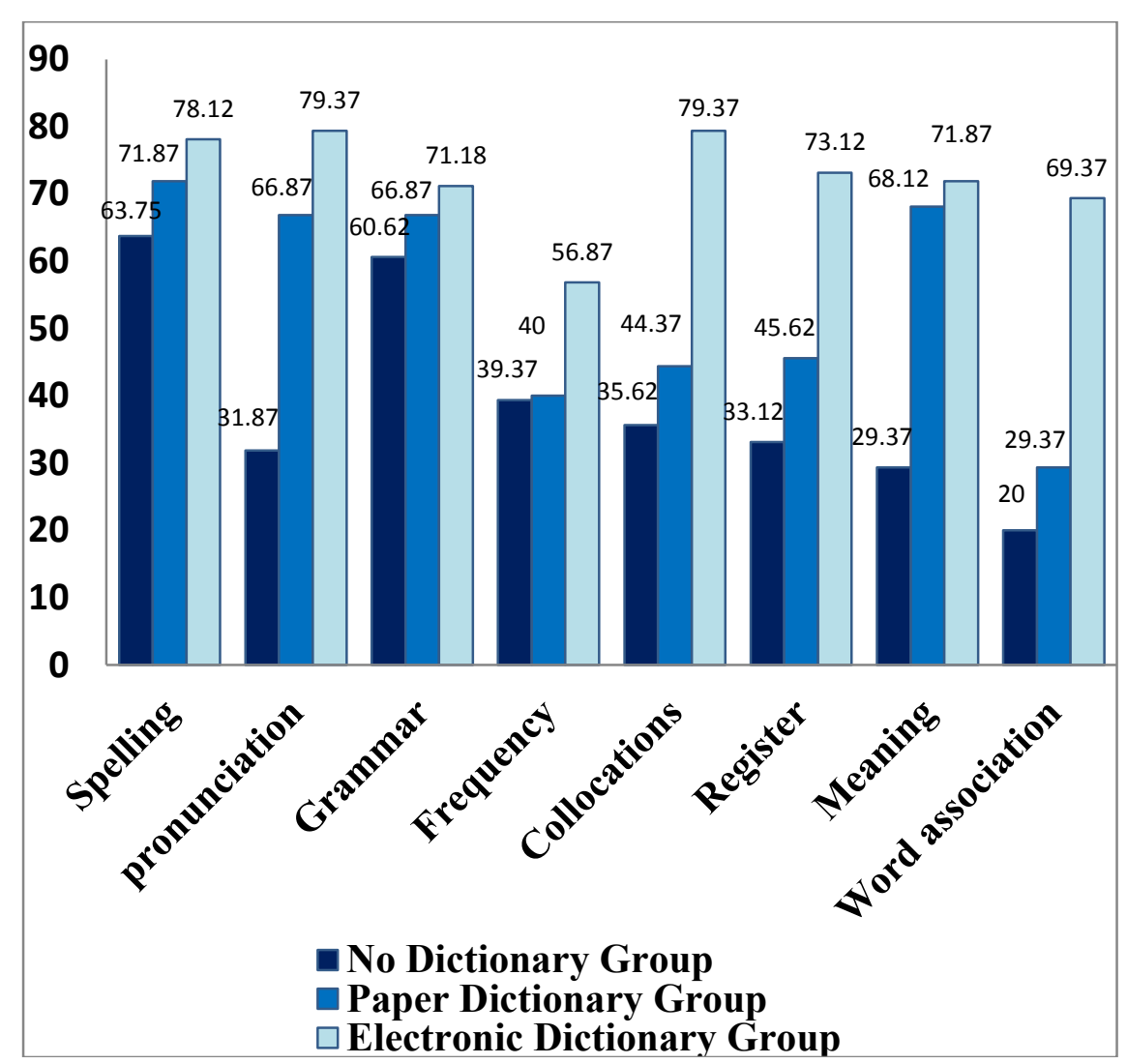

Graph 01: Students In-depth Word Knowledge Developments

In the spelling task, the results of students in the three groups (no dictionary group paper dictionary group and electronic dictionary group) were not significantly different ( $63.75 \%$ vs. $71,87 \%$ vs. $78,12 \%$ of correct answers respectively). Students seem not to use their dictionaries to look up words' spellings while reading as these are originally provided in the text. Learning words' spellings may be due to noticing the words in the reading material rather than dictionary consultation in all groups. Dictionary access for other types of information may have reinforced the spelling knowledge of students in the paper and electronic dictionary groups as the spelling of a word is normally the first kind of information that a dictionary user will see. Words' spellings are provided in the entries. In paper dictionaries, spellings are generally obvious (typed in bold) to help users find the target words in the dictionary' page and to make the entry stand out from the other text. In electronic dictionaries, spellings are also clearly visible. They are usually presented in bold and in colour or in a different print as a means to highlight the target word. 
The results of the exercise assessing pronunciation knowledge indicate that there was a significant difference between the no dictionary group in opposition to the paper and electronic dictionary groups. The average percentage of correct answers in the no dictionary group was very low; only 31 , $87 \%$ of students answered correctly. This suggests that guessing the pronunciation of unknown words is very difficult. Students in the no dictionary group were unable to guess the correct pronunciation of even very simple words whose pronunciation corresponds to their spelling. This is a major problem as the mastery of pronunciation is key to successful communication. On the other hand, $66,87 \%$ of the answers in the printed dictionary group and $79,37 \%$ of the answers in the electronic dictionary group were correct. Comparing these results, we note that the electronic dictionary group resulted in the highest percentage of correct responses. As the pronunciation of English cannot generally be guessed from its spelling, phonetic transcriptions seem to be checked by the participants with dictionary access. Though phonetic transcriptions might be of technical character, dictionary' users in this study do not seem to find it challenging to interpret the signs; they are advanced learners who might have acquired some familiarity with the principles of phonetics in the course of their language study or they might have taken advantage of the dictionary' front matter or appendices which contain phonological information. Moreover, the sound option in the electronic dictionary can be very functional in learning words' pronunciations. The double presentation of pronunciation in the IPA transcription and the recorded pronunciation of a native speaker of English seem to improve the results of the electronic dictionary' users.

The results for exercise three indicate a slight difference among the participants in the three groups. 60,62\% of the participants in the no dictionary group were able to indicate the correct word class. In the paper and electronic dictionary groups, the subjects were also largely relatively successful in naming words' classes. The average percentage of correct answers in the electronic dictionary group was $71(18 \%)$, slightly higher than the average percentage of correct answers in the paper dictionary group (66.87\%). These results may indicate that the context in which the word occurs can be somehow helpful in determining its function and hence its word class. This does not bury the importance of learners dictionaries as a resource of grammatical information. Dictionaries indicate the word class by the abbreviation of the part-of-speech. In electronic dictionaries, the word class is generally spelled out because there are no space limits. Paper or electronic dictionaries might help in confusing situations. The fact that such information is included also implies that the user is going to use the dictionary in order to improve his productive use of language. 
The results for exercise four revealed that the participants, without access to dictionaries, were able to make accurate guesses about the frequency of some words. $39.37 \%$ of the answers in the no dictionary group gave the accurate frequency rating to the various words in the test. Subjects in the paper and electronic dictionary groups did slightly better ( $40 \%$ and $56,87 \%$ orderly). So, most paper dictionaries do not seem to provide words' frequency values. In addition, though a lot of electronic dictionaries are now compiled on the basis of large text corpora and more and more information about the frequency is provided, the frequency knowledge development in the electronic dictionary group might be still low. Participants in all groups (no dictionary group, paper dictionary group, and electronic dictionary group) might have used their frequency intuitions or L1 frequencies to answer the exercise. Information on frequency is particularly valuable for language learners, as it immediately indicates how important it is to learn a word. Students should be taught and encouraged on how to check such type of information in their modern dictionaries. So, frequency should be given greater importance in dictionaries.

Collocation is a difficult area for EFL learners. The findings of our study indicate that $64,38 \%$ of the answers in the no dictionary group were unsatisfactory; only $35,62 \%$ could predict the correct collocates of the target words. This may indicate that collocations cannot be learnt implicitly while reading. Likewise, only $44,37 \%$ of students in the paper dictionary group answered correctly. In most paper dictionaries, collocations are generally provided in examples. Learners, however, might sometimes find it difficult to figure out the words' collocations from the examples. This can be due to the fact that examples have many functions at a time as supplementing definitions and showing words use in context. On the other hand, 79, 37\% of students' responses in the electronic dictionary group were correct. This can be a result of technology advancement and developments in corpus linguistics. Now, electronic dictionary' compilers are able to provide more information on collocations separately as in dedicated collocation boxes and this seems to be very useful in the process of learning vocabulary.

The results for exercise six indicate that there is a significant difference between students in the no dictionary group and the paper dictionary group in opposition to those in the electronic dictionary group. Most participants in the no dictionary group $(33,12 \%)$ failed in their choice of words, and so made inappropriate choices for the contexts provided, which denote a serious incompleteness of communicative competence. Likewise, only $45,62 \%$ of the answers in the paper dictionary group were correct. On the other hand, 73.12\% of the answers in the electronic dictionary group were correct. These results suggest that words' usage restrictions cannot be acquired through reading and that paper dictionary use is still unhelpful in providing information on words usage though it remains difficult to find usage information once it is provided 
in examples. Electronic dictionary use, however, seems to be extremely helpful in providing such kind of information.

As evident from the results in the graph above, the average percentage of students giving correct answers in the no dictionary group was very low $(29.37 \%)$. On the other hand, $68.12 \%$ of the answers in the printed dictionary group and $71.87 \%$ of the answers in the electronic dictionary group were correct. This suggest that guessing words from context did not help students learn words' meaning either because the surrounding context contained too many unknown words or the participants made erroneous inferences, or tried to ignore the unknown words while reading. So, it goes without saying that dictionaries are among the best resources used by EFL learners to learn words meanings. These findings also support research studies stating that a high percentage of dictionary users use this resource to look up word definitions. The results also indicate that the type of the dictionary, whether computerized or printed has affected students' responses as well. The amount and the presentation of information and the provision of pictures and media may have helped the electronic dictionary users to be the best.

Finally, In the word association exercise, the average percentage of correct responses in the no dictionary group $(20 \%)$ and the paper dictionary group $(29,37 \%)$ was much lower than the average percentage of correct responses in the electronic dictionary group $(69,37 \%)$. Paper dictionaries seem to be less satisfactory than electronic dictionaries in providing words' associations. Information on word associations appears to be absent in paper dictionaries. This can be mainly due to space limitations. On the other hand, as electronic dictionaries generally do not suffer from space restrictions, they seem to provide information on words associations. So, such type of dictionaries must be promoted, as Hatch and Brown [27] noted that the better learners used the dictionary extensively to learn not just the word they originally started to look up but also related words.

In a nutshell, the results of the study indicate that dictionary use results in important improvements in students' in-depth vocabulary knowledge. Electronic dictionary use leads to the greatest vocabulary gains. Paper and electronic dictionaries seem to provide, in varying degrees, valuable information on the different word knowledge aspects. The results of the experiment do not suggest that guessing and using dictionaries are not mutually exclusive. Students can, guess first, then consult a dictionary to check on the guess. Consequently, they may avoid the negative effects of inaccurate guessing and reinforce their impression of the words.

\section{Conclusion}


Recognizing the word meaning is only one aspect of word knowledge. Dictionaries, especially electronic ones, are an effective tool to widen students' vocabulary knowledge. So, students need their teachers' guidance to use their dictionaries effectively, to notice the different aspects of vocabulary knowledge, and become familiar with the new types of reference materials and incorporate them in the teaching/ learning context.

\section{References}

[1]- Schmitt, N., \& McCarthy, M. (eds.). (1997). Vocabulary: Description, Acquisition and Pedagogy. Cambridge: Cambridge University Press.

[2]- Nation, P. (1990). Teaching and Learning Vocabulary. Boston: Heinle \& Heinle.

[3]- Stahl, K. A. D., \& Bravo, M. (2010). Contemporary Classroom Vocabulary Assessment for Content Areas. Reading Teacher, 66(7), 566578.

[4]- Hunston, S., Francis, G., \& Manning, E. (1997). Grammar and Vocabulary: Showing the Connections. ELT Journal, 51(3), 208-216.

[5]- Ordonez, C. L., Carlo, M. S., Snow. C. E. \& Mclaughiin, B. (2002). Depth and Breadth of Vocabulary Knowledge in Two languages: Which Vocabulary Skills Transfer? Journal of Educational Psychology, 94, 719728.

[6]- Summers, D. (1988). The Role of Dictionaries in Language Learning. In R. Carter \& M. McCarthy (Eds.), Vocabulary and Language Teaching (pp. 111- 125). London: Longman.

[7]- Honeyfield, J. (1977). Simplification. TESOL Quarterly, 11, 431-440.

[8]- Miller, G. A., \& Gildea, P. M. (1987). How Children Learn Words. Scientific American, 257(3), 94-99.

[9]- McCarthy, M. \& Dolezal, F. (1999). A Study of Dictionary Use by

ESL Students in an American University. International Journal of Lexicography 12(2): 107-145.

[10]- Nist, S. L., \& Olejnik, S. (1995). The Role of Context and Dictionary Definitions on Varying Levels of Word Knowledge. Reading Research Quarterly,30(2), 172-192.

[11]- Knight, S. (1994). Dictionary Use while Reading: the Effects on Comprehension and Vocabulary Acquisition for Students of Different Verbal Abilities. The Modern Language Journal, 78(3), 285-299.

[12]- Hulstijn, J., Hollander, H., \& Greidanus, T. (1996). Incidental Vocabulary Learning by Advanced Foreign Language Students: the Influence of Marginal Glosses, Dictionary Use, and Reoccurrence of Unknown Words. The Modern Language Journal, 80(3), 327-339.

[13]- Cubillo, M. C. (2002). Dictionary Use and Dictionary Needs of ESP Students: an Experimental Approach. International Journal of Lexicography, 15(3), 206-228. 
[14]- Sökmen, A. J. (1997). Current Trends in Teaching Second Language Vocabulary. In N. Schmitt \& M. McCarthy (Eds.), Vocabulary: Description, Acquisition and Pedagogy (pp. 237-257). Cambridge: Cambridge University Press.

[15]- Neubach, A., \& Cohen, A. D. (1988). Processing Strategies and Problems Encountered in the Use of Dictionaries. Dictionaries, 10, 1-19.

[16]- Fraser, C. A. (1997). The Impact of Lexical Processing Strategy Instruction on 12 Readers' Strategy Use, Reading Rate, Reading Comprehension, and Vocabulary Learning. (Unpublished doctoral dissertation).

[17]- Cowie, A. P. (1999). English Dictionaries for Foreign Learners: A History. . Oxford: Clarendon Press.

[18]- Atkins, B. T. S. (Ed). (1998). Using Dictionaries: Studies of Dictionary Use by Language Learners and Translators. Tübingen: Niemeyer.

[19]- Kirkness, A. (2004). Lexicography. In A. Davies \& C. Elder (eds.), The Handbook of Applied Linguistics (pp. 54-81). Oxford: Blackwood Publishing Ltd.

[20]- Hartmann, R. R. K. (1987). Four Perspectives in Dictionary Use: a Critical Review of Research Methods. In A. P. Cowie (ed.), The Dictionary and the Language Learner (pp. 11-28). Tübingen: Max Niemeyer.

[21]- Nesi, H. (2000). The Use and Abuse of EFL Dictionaries. Tübingen: Niemeyer.

[22]- Taylor, A., \& Chan, A. (1994). Pocket Electronic Dictionaries and Their use. In W. Martin, W. Meijs, M. Moerland, E. ten Pas \& P. van Sterkenburg...Vossen (Eds.), Euralex 1994 Proceedings: Papers Submitted to the 6th EURALEX International Congress on Lexicography in Amsterdam, The Netherlands (p. 598-605). Amsterdam: Euralex.

[23]- Koga, Y. (1995). The Effectiveness of Using an Electronic Dictionary in Second language Reading. Bulletin of the Liberal Arts of Hiroshima University, 44, 239-244.

[24]- Carr, M. (1997). Internet Dictionaries and Lexicography. International Journal of Lexicography, 10(3), 209 - 221.

[25]- Weschler, R., \& Pitts, C. (2000). An Experiment Using Electronic Dictionaries with EFL Students. The Internet TESL Journal, 6(8), retrieved from http://iteslj.org/Articles/Weschler-ElectroDict.html.

[26]- Sharpe, A. (1988). Pragmatic Considerations for an English-Japanese Dictionary. International Journal of Lexicography, 2(4), 315-323.

[27]- Hatch, E. \& Brown, C. (1995). Vocabulary, Semantics, and Language Education. Cambridge: Cambridge University Press. 